\title{
Study of classification and estimation models for soil loss disturbed by engineering construction
}

\author{
Duihu Ning *, Xiaoying Liu, Pengfei Du \\ International Research and Training Center on Erosion and Sedimentation, China Institute of Water Resources \\ and Hydropower Research, Beijing, China \\ *Corresponding author e-mail : dupf@mail.bnu.edu.cn \\ Received : 14.12.2013 \\ Accepted: 14.04.1014
}

\begin{abstract}
Growing interest in the research of soil loss caused by human activities has attracted public attention over the world especially for the developing countries. However, existent soil erosion estimation models focused on natural than artificial conditions, and particularly the models used to estimate the soil erosion rate to the latter involves a number of uncertainties, which require further attention. To develop scientific models, it is necessary to extract the characteristics of soil bodies that formed in different engineering construction programs. This contribution reports the results of an investigation of classifications in various artificial programs around China. Some indexes, such as slope gradient, slope length, soil layer depth, vegetation coverage were measured for accumulated spoil and cutting edges, which were caused in the process of construction. Soil samples were also collected from different sites representative of different types of projects and distributed in different areas of China. Measurements of soil density and soil particle size were made on these samples. Four classifications were given and related experiments, including artificial simulation rainfall, field wind tunnel simulation were taken to calculate the influence of wind factors on erosion modulus and to estimate the change of different disturbance times. On the basis of analyzing, the crucial parameters to contribute soil loss were selected and the models framework using for calculating different types soil erosion were put forward.
\end{abstract}

Key Words: Soil erosion induced by human, soil disturbance, engineering construction, erosion modelling, parameter selection

\section{INTRODUCTION}

With the development of economy and society, numerous construction projects have been launched over the world in the last several decades. Take China as an example, nearly 2-5 million $\mathrm{m}^{3}$ of construction spoils are produced for per $100 \mathrm{~km}$ of highway construction (Dong et al., 2011 ), which is only a little part for all types construction. During 2001-2005, there were about 80,000 construction projects started to enforce, total area is greater than $50,000 \mathrm{~km}^{2}$. This kind human activity has been resulted in apparent impacts on the environment and soil stability (Forman and Deblinger, 2000). Hence, soil loss associated with the soil disturbed by engineering construction processes has attracted more attentions due to its high erosion rates (e.g. Storey et al. 1996; Chen et al., 2009; Bhattarai et al., 2011 ).

In most U.S. construction sites, where have an erosion rate of approximately 20-200 tons per acre per year, a rate that is about 3 to 100 times that of croplands (Burton and Pitt, 2002) and 2 to 4000

times greater than pre-construction sites (Jon Harbor, 1999). According to study results from SEWRPC, construction was the first or second largest sediment contributor (1978). Willett estimated that about 350 million tons of sediment reached U.S. surface waters annually generated in urban construction (1980), increased with 3 times compared to the result from US Geological Survey in seventies of last century (1970). More recently, US Environmental Protection Agency reported that erosion happened in various construction sites can reach as much as 500 fold while compared to undisturbed natural areas (USEPA, 2005).

To avoid severe erosion from construction sites, a series of measures have been enforced such as vegetated buffers and mulches, natural fiber mats placement, retention or detention basins and ponds (Hogan and Walbridge, 2007; Houser and Pruess, 2009). These practices decreased or controlled the erosion to a great extent through reducing runoff. Noura Bakr et al. (2012) confirmed the effectiveness 


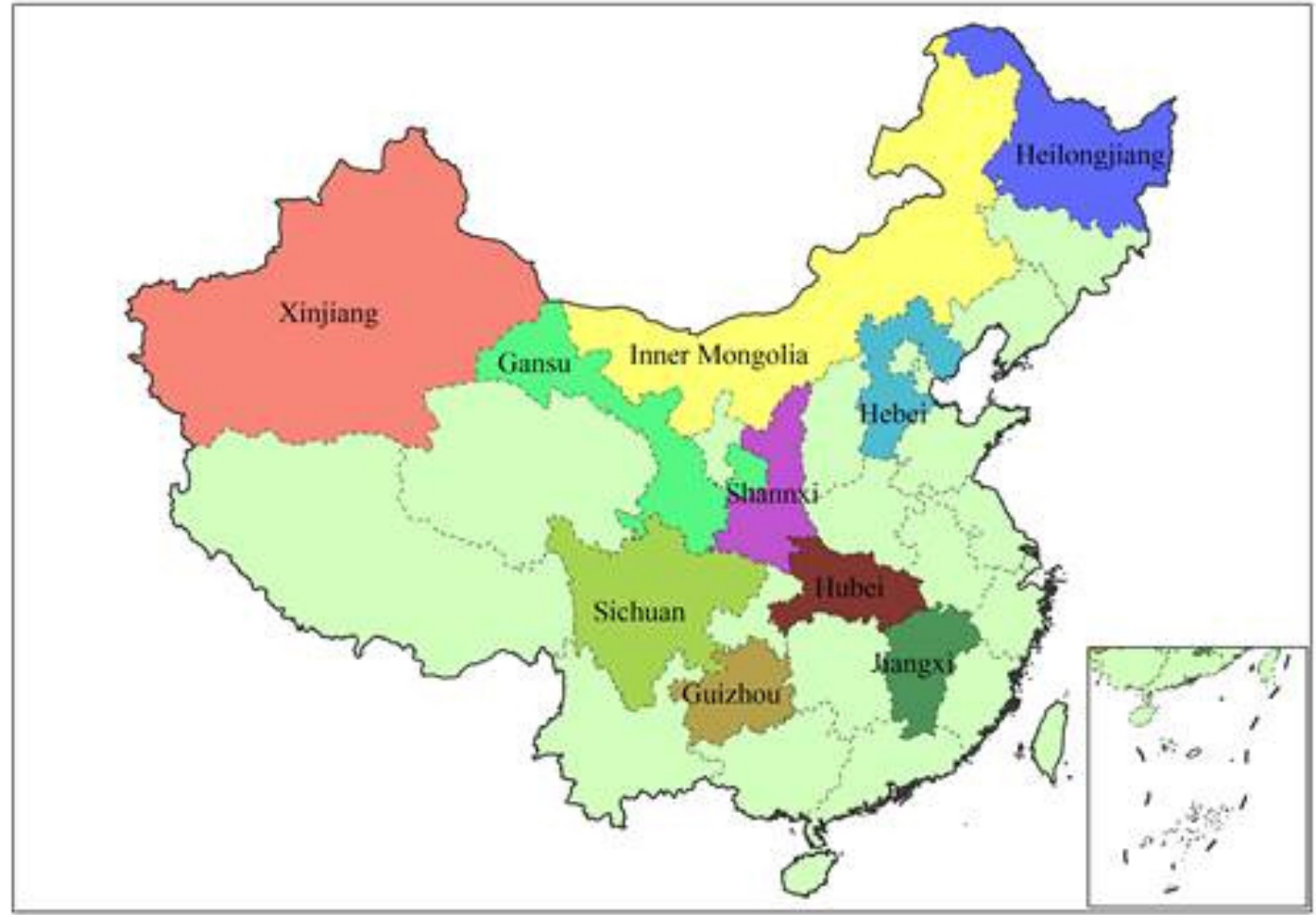

Figure 1. Field survey distributed across China

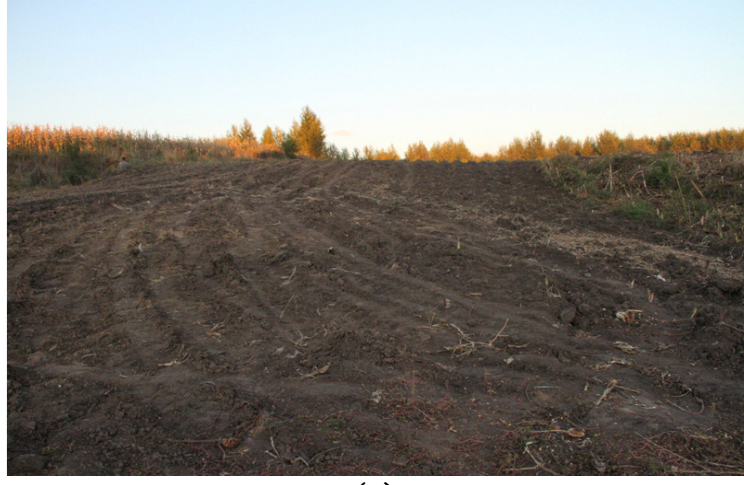

(a)

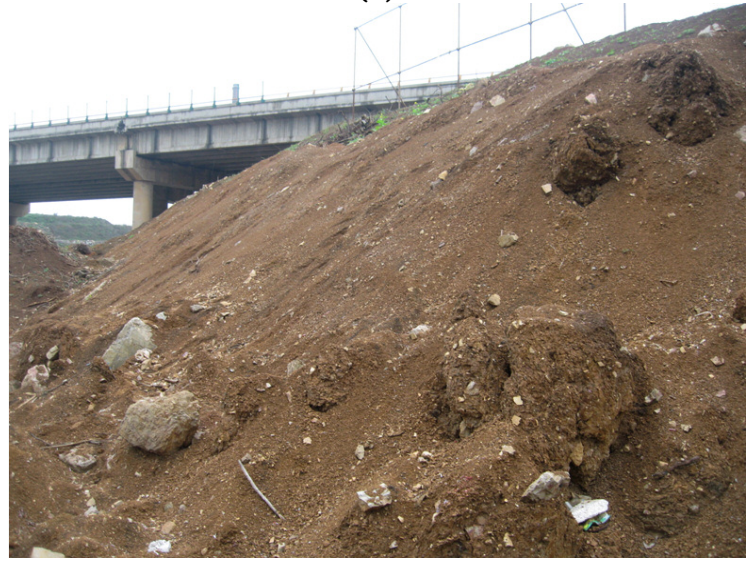

(c)

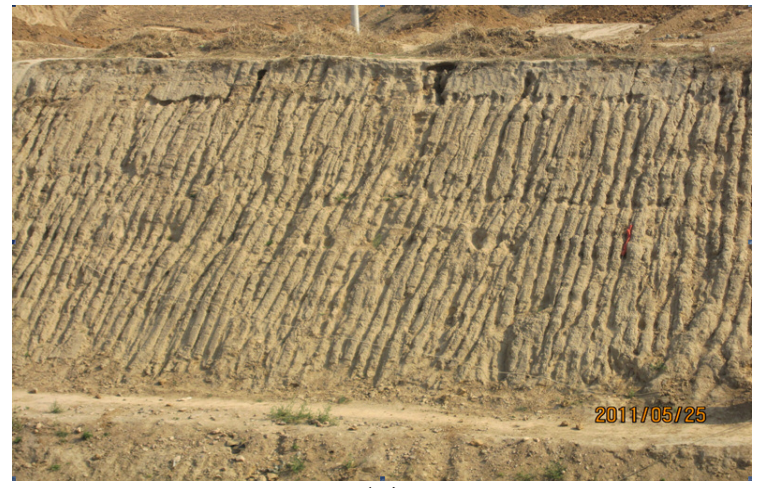

(b)

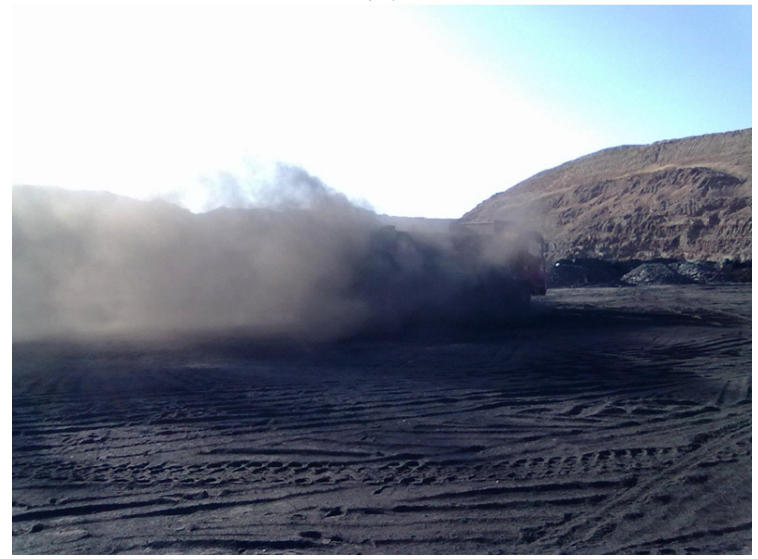

(d)

Figure 2. Typical construction sites, which has great erosion potential. (a) cropland after turning up in Heilongjiang province. (b) cutting edge for irrigation ditch after a rain season in Hebei province. (c) spoil soil without any erosion controls in Guizhou province. (d) soil wind erosion was severe during the mining in Inner Mongolia. 
via evaluation of compost/mulch as highway embankment erosion control at the plot scale.

To obtain accurate erosion rate for construction site is important (Xu et al., 2009). However, there is almost blank in models research for estimating specific soil erosion amount from construction sites because the various construction types and diverse characteristics. In this circumstance, to contribute soil erosion models in construction sites, all kinds of construction sites were investigated across China, general characteristics were also summarized, and crucial parameters were selected through developing a series of experiment in labs and fields. This paper reports the preliminary achievements.

\section{MATERIAL AND METHODS}

\section{Construction sites survey}

470 typical construction sites across China were chosen on the basis of collection and summarizing soil disturbance of engineering construction from National Soil and Water Supervision Agency. The survey sites distributed in ten provinces including Heilongjiang, Hebei, Inner Mongolia, Xinjiang, Gansu, Shannxi, Sichuan, Guizhou, Jiangxi and Hubei (Fig. 1). Soil disturbance types cover railway, motorway, tubes, mining, hydropower, factory, cropland and urban construction. Some typical pictures for constructions surveys are shown in Fig.2.

\section{Indexes measurement and samples collection}

During investigation in these sites, some indexes such as slope gradient, slope length, vegetation covers, soil depth were measured, and samples (ca.300 g) of the surface soil $(0-5 \mathrm{~cm}$ ) were collected from each construction site on up-slope, middleslope and down-slope positions respectively used for analysis of soil properties, using a stainless steel trowel, which was repeatedly cleaned to avoid

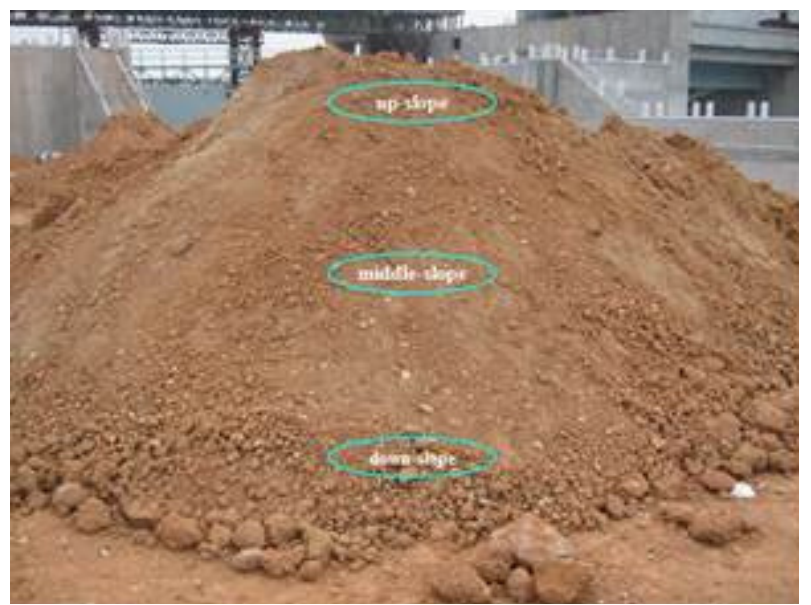

Figure 3. Positions to collect soil samples cross-contamination of the samples. In some sites, the cutting rings were used to collect samples for density analysis. Samples collection points in a typical construction site slope were shown in Fig. 3.

\section{Laboratory analysis}

The density was measured firstly while samples collected from the study field were returned to the laboratory. Then the surface samples were sieved 2 $\mathrm{cm}$ for stone analysis. Subsequently, all samples were air dried, disaggregated using a pestle and mortar, sieved to $2 \mathrm{~mm}$ and homogenised. Finally, particle size was measured after removal of organic material.

\section{Fields Experiment}

During October 2010 and August 2011, to make clear the characteristics of soil in constructions sites, 20 times artificial rainfall were taken in four underlying surface of cutting edge and 30 times artificial rainfall were placed in different accumulative spoils. The experiment equipment used was made in Institute of soil and water conservation of Chinese Science Academy and Ministry of Water Resources of China. The structure is supported by four telescopic legs and the simulator was covered with a plastic curtain to protect the experiments against wind. The water from the nozzle falls onto a squared area reach up to $1200 \times 300 \mathrm{~cm}^{2}$.

For the experiments in cutting edges, basic parameters were set up as follows: rainfall intensity was classified into $0.5,1.0,1.5$ and $1.8 \mathrm{~mm} \mathrm{~min}^{-1}$ four grades, total rainfall amount was controlled at or about $45 \mathrm{~mm}$, sampling intervals were each a min in the first 3 min of runoff producing, each for every two min in the periods of 4 to 7 min of runoff producing, each for every three min in the periods of 8 to 10 min of runoff producing, and each for every five min since the 11 th $\min$ of runoff producing until the experiment is over.

For the precipitation happened in accumulative spoil, samples collected from construction sites were put in a steel container with rectangle parallelepiped shape (3 m length, $1 \mathrm{~m}$ width and $1 \mathrm{~m}$ depth) as the underlying surfaces, which include pure soil body, and stone-soil mixed body with ration 0.5 and 2. Slope gradient was set up at $35^{\circ}$ and $40^{\circ}$ according to previous investigation results. Rainfall intensity was classified into 1.0, 1.5, 2.0, 2.5, 3.0 $\mathrm{mm} \mathrm{min}{ }^{-1}$ five grades. Sampling intervals were each a min in the first 3 min of runoff producing, and each for every three min since the $4^{\text {th }}$ min of runoff producing until the experiment is over. Each precipitation persists $45 \mathrm{~min}$. 
Soil moisture and disturbance time were considered to take place field wind tunnel experiments in the construction site located in Lanzhou, Gansu province. The wind tunnel equipment was designed and made by the key lab of desert and desertification in cold and arid regions environmental and engineering institute, Chinese Academy Sciences. The tunnel has a total length of $37 \mathrm{~m}$ with a working section of $21 \mathrm{~m}$. The cross-section of the working section was 1.2 $\mathrm{m} \times 1.2 \mathrm{~m}$. Free wind speed can be continuously adjusted from 1 to $40 \mathrm{~m} \mathrm{~s}^{-1}$. Sampling height distributed in 0 to $60 \mathrm{~cm}$ above the surface with 1 $\mathrm{cm}$ increment. Sampling time intervals are every 2 seconds.

\section{RESULTS AND DISCUSSION}

\section{Slope gradient of cutting edges}

All slope gradients are distributed in the section of $10^{\circ}$ to $90^{\circ}$. Fig. 4 shows the percentage of different gradients according to the field survey for cutting edges. The most frequent gradient was between $30^{\circ}$ and $70^{\circ}$.

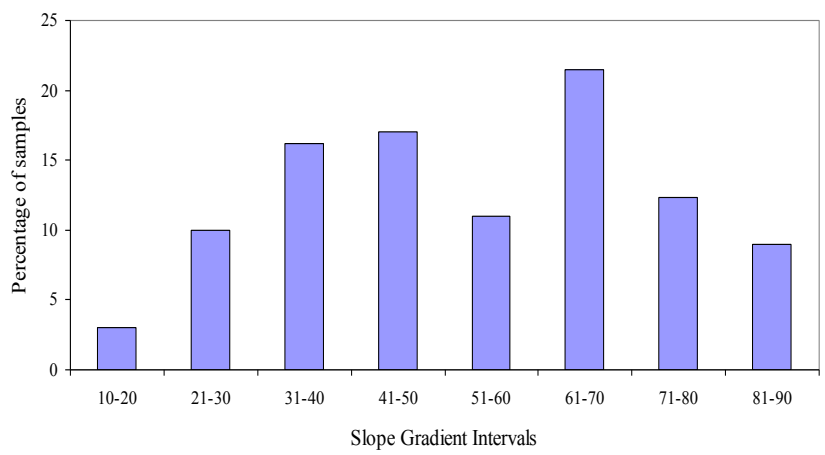

Figure 4. Slope Gradient Distribution of Cutting Edges

\section{Slope length of cutting edges}

$10 \mathrm{~m}$ and $20 \mathrm{~m}$ are two important critical lengths. About half slope lengths are shorter than $10 \mathrm{~m}$ while only $23.45 \%$ of slope lengths is greater than $20 \mathrm{~m}$. The distribution of slope length of cutting edges is shown in Fig. 5.

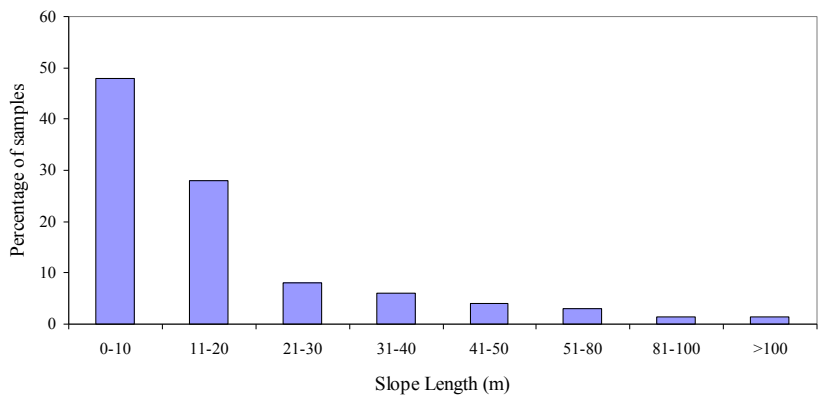

Figure 5. Slope length Distribution of Cutting Edges

\section{Soil depth of cutting edges}

Soil depths of cutting edges are mainly greater than $100 \mathrm{~cm}$, which account for about $42.9 \%$ of total depths. The distribution of depths is as follows.

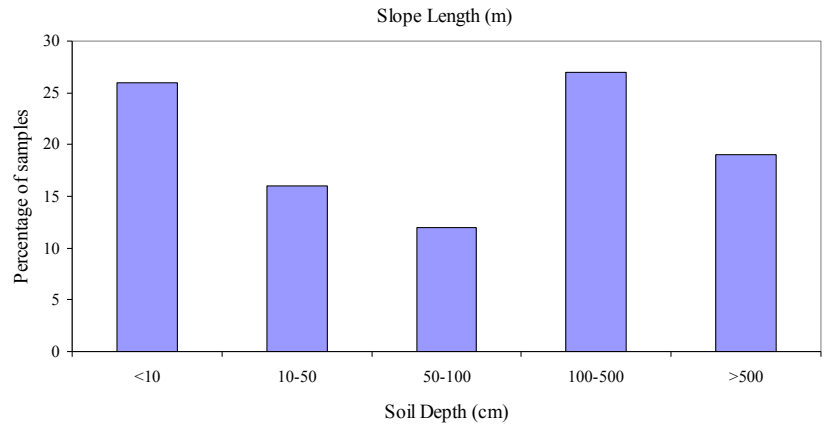

Figure 6. Soil Depths of Cutting Edges

\section{Soil density of cutting edges}

According to density measurement, the results of density for cutting edges ranged from 1.01 to 1.74. The most frequent density is between 1.21 and 1.60 , samples density is greater than 1.61 only account for 9\%. Results are shown in Fig 7.

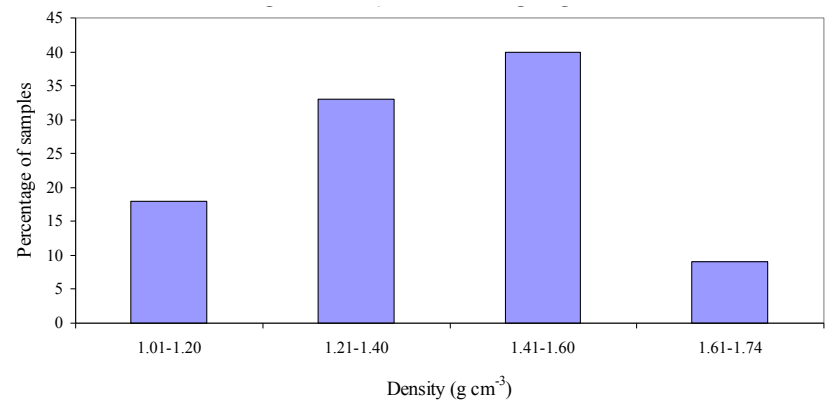

Figure 7. Soil Density of Cutting Edges

\section{Stone percentage of cutting edges}

About half cutting edges are consisted by little stone $(<20 \%)$ and most soil. This reflects that construction activities prefer to choose those sites with more soil to cut or dig. The distribution of stone percentage in cutting edges is shown as Fig. 8.

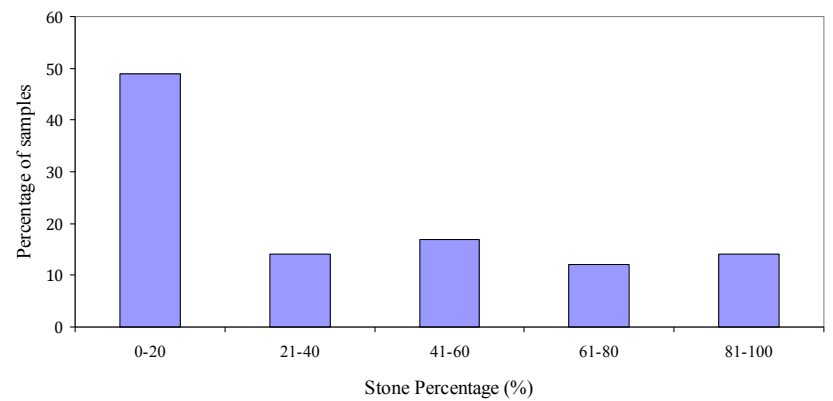

Figure 8. Stone Percentage of Cutting Edges 


\section{Particle size of soils from cutting edges}

All samples from cutting edges were analysed for particle size, the results are shown in Tab. 1. It is obvious that there are no rules in different construction sites. This suggests that a great discrepancy exist in cutting edges.

Table 1. Particle size analysis results for cutting edges (\%)

\begin{tabular}{|c|c|c|c|c|c|c|c|c|c|}
\hline No. & $>5 \mathrm{~mm}$ & $\begin{array}{l}2 \mathrm{~mm}- \\
5 \mathrm{~mm}\end{array}$ & $\begin{array}{c}2 \mathrm{~mm}- \\
1 \mathrm{~mm}\end{array}$ & $\begin{array}{c}1 \mathrm{~mm}- \\
500 u m\end{array}$ & $\begin{array}{l}500 u m \text { - } \\
300 u m ~\end{array}$ & $\begin{array}{c}300 u m \text { - } \\
100 u m\end{array}$ & $\begin{array}{c}100 u m \text { - } \\
50 u m\end{array}$ & $\begin{array}{l}50 u m \text { - } \\
25 \mathrm{um}\end{array}$ & $<25$ um \\
\hline 1 & 23.10 & 35.63 & 22.49 & 13.33 & 4.75 & 0.70 & 0.00 & 0.00 & 0.00 \\
\hline 2 & 35.89 & 11.29 & 10.85 & 13.73 & $9 \cdot 37$ & 8.42 & $4 \cdot 37$ & 5.17 & 0.91 \\
\hline 3 & 24.74 & 17.70 & 18.28 & 15.47 & 6.98 & 6.69 & 6.13 & 3.76 & 0.25 \\
\hline 4 & 0 & 24.93 & 19.00 & 17.82 & 12.10 & 12.18 & 7.01 & 7.14 & 1.04 \\
\hline 5 & 47.83 & 24.14 & 16.23 & 9.83 & 3.42 & 2.06 & 0.43 & 0 & 0.01 \\
\hline 6 & $5 \cdot 59$ & 25.53 & 24.18 & 11.53 & 7.50 & 14.78 & 5.76 & 4.21 & 0.93 \\
\hline 7 & 12.26 & 37.83 & 20.11 & 12.15 & 6.17 & 7.84 & 2.52 & 1.09 & 0.03 \\
\hline 8 & 4.12 & 35.15 & 23.86 & 16.18 & 8.66 & 8.18 & 2.22 & 1.56 & 0.08 \\
\hline 9 & 13.26 & 26.78 & 19.01 & 16.20 & $9 \cdot 37$ & 10.00 & 3.65 & 1.71 & 0.03 \\
\hline 10 & 47.78 & 30.19 & 12.56 & $5 \cdot 39$ & 1.86 & 1.46 & 0.42 & 0.33 & 0.01 \\
\hline 11 & 34.30 & 27.54 & 15.13 & 9.83 & $4 \cdot 39$ & 4.63 & 2.23 & 1.85 & 0.10 \\
\hline 12 & 34.07 & 23.88 & 17.41 & 11.85 & 4.66 & 4.40 & 2.90 & 0.82 & 0.02 \\
\hline 13 & 0.84 & 20.11 & 30.61 & 21.68 & 10.50 & 11.60 & 3.13 & 1.35 & 0.19 \\
\hline 14 & 38.71 & 26.87 & 14.01 & 9.01 & 4.62 & 4.49 & 1.26 & 0.95 & 0.06 \\
\hline 15 & 6.19 & 31.59 & 29.41 & 16.05 & 8.18 & $7 \cdot 34$ & 0.98 & 0.24 & 0.00 \\
\hline 16 & 60.68 & 19.22 & 9.98 & 5.66 & 2.15 & 1.55 & 0.45 & 0.29 & 0.02 \\
\hline 17 & 39.33 & 23.16 & 13.88 & 10.62 & 5.77 & 5.22 & 1.48 & 0.53 & 0.01 \\
\hline 18 & 19.17 & 31.21 & $19 \cdot 37$ & 11.41 & 5.06 & 7.77 & 3.93 & 1.84 & 0.25 \\
\hline 19 & 37.82 & 34.13 & 14.45 & 7.61 & 3.18 & 2.37 & 0.37 & 0.07 & 0.00 \\
\hline 20 & 13.45 & 22.28 & 17.98 & 17.93 & 11.68 & 12.79 & 2.44 & 1.37 & 0.08 \\
\hline 21 & 47.71 & 13.73 & 7.32 & 6.79 & 5.72 & 10.21 & 6.18 & 2.17 & 0.17 \\
\hline 22 & 27.27 & 39.56 & 15.74 & 7.80 & 3.30 & 4.23 & 1.61 & 0.47 & 0.02 \\
\hline 23 & 0.49 & 14.42 & 29.62 & 24.31 & 12.29 & 12.13 & 4.39 & 2.17 & 0.17 \\
\hline 24 & 21.11 & 23.68 & 17.77 & 13.56 & 7.30 & 8.61 & 4.73 & 2.73 & 0.53 \\
\hline 25 & 30.87 & 28.93 & 15.95 & 10.79 & 5.66 & 5.23 & 2.13 & 0.42 & 0.01 \\
\hline 26 & 6.26 & 14.25 & $25 \cdot 32$ & 20.16 & 8.53 & 9.22 & 9.23 & 6.42 & 0.61 \\
\hline 27 & 34.38 & 24.22 & 14.61 & 10.46 & 5.36 & 5.33 & 3.72 & 1.80 & 0.14 \\
\hline 28 & 6.32 & 20.16 & 24.14 & 20.92 & 11.81 & 10.29 & 3.90 & 2.25 & 0.20 \\
\hline 29 & 6.29 & 16.73 & 24.88 & 19.08 & 11.94 & $13 \cdot 30$ & 4.48 & 3.13 & 0.18 \\
\hline
\end{tabular}

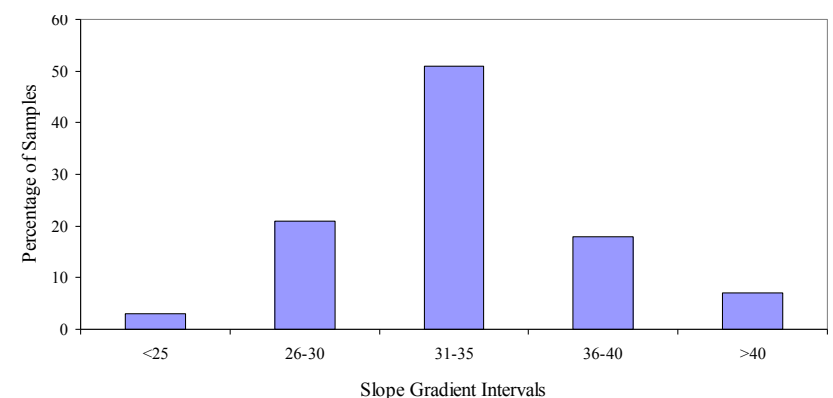

Figure 9. Slope Gradient Distribution of Accumulative spoils

\section{Slope gradient of accumulative spoil}

Generally, the slope gradient of accumulative spoil is the natural angle of repose, which depends upon texture of soils. The more clay content is, the more natural angle of repose will be. The slope gradient results for investigated accumulative spoil are shown in Fig. 9. 


\section{Slope length of accumulative spoil}

On site survey results shows that most often slope length for accumulative spoil is between 2 and $5 \mathrm{~m}$, account for $50.3 \%$ of total samples. Slope length greater than $10 \mathrm{~m}$ is only about 3\%, this is because that an artificial cutting is quite popular while several short slopes replace of a long slope through building platforms inter it.

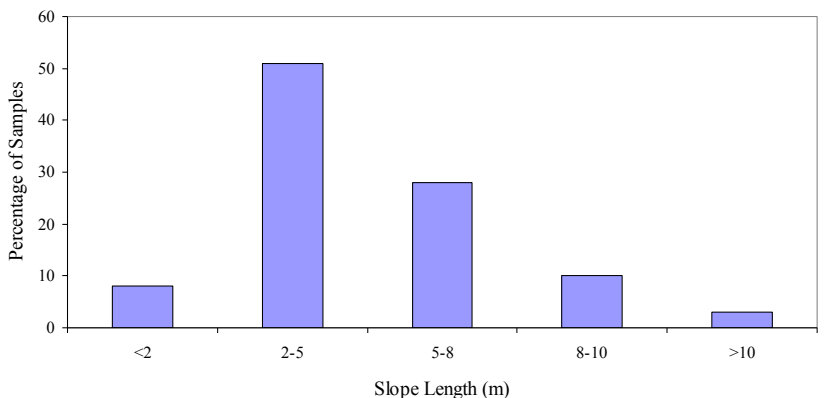

Figure 10. Slope Length Distribution of Accumulative spoils

Particle size of soils from accumulative spoil

Particle size results for two categories underlying surfaces are shown as Fig. 11. The highest content

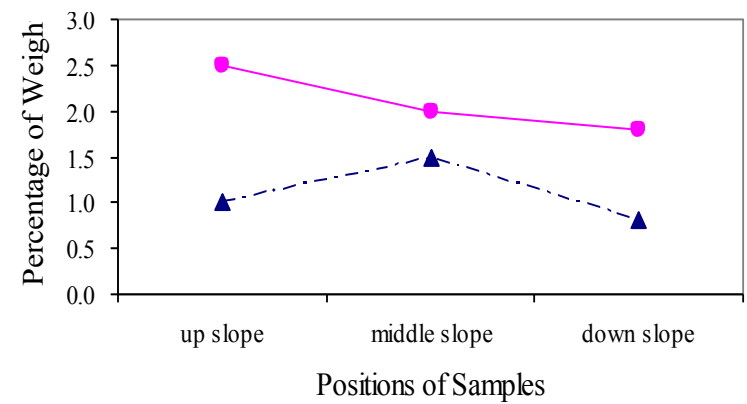

(a)

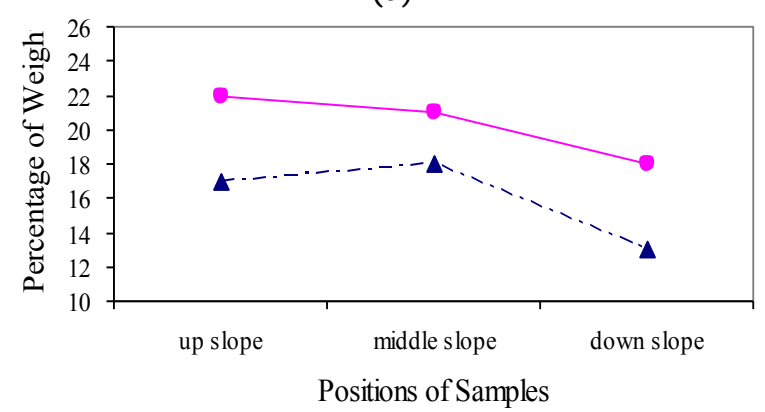

(c)

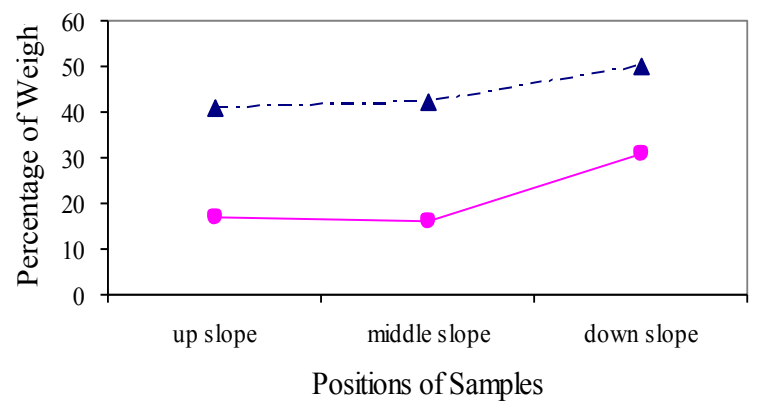

(e) is the particle greater than $10 \mathrm{~mm}$ while the lowest proportion happen on the particle smaller than $0.2 \mathrm{~mm}$. There are no rules not only for the different underlying surfaces but also for the various positions.

\section{Sediment yields for cutting edges with different underlying surfaces in various rainfall intensities}

The erosion amounts in different underlying surface cutting edges were calculated under various rainfall intensities via artificial precipitation experiments. The results were shown in Fig. 12. It can be seen that sediment yields were got up with the increasing of rainfall intensities in cutting edges with silt, sandy and geotechnical underlying

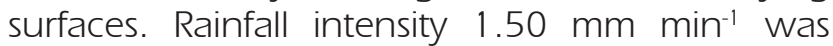
become an important inflection point, the erosion amounts were reduced to a great extent after this intensity. Generally, the highest sediment yield happened in the cutting edge with geotechnical as underlying surface under the high rainfall intensities.

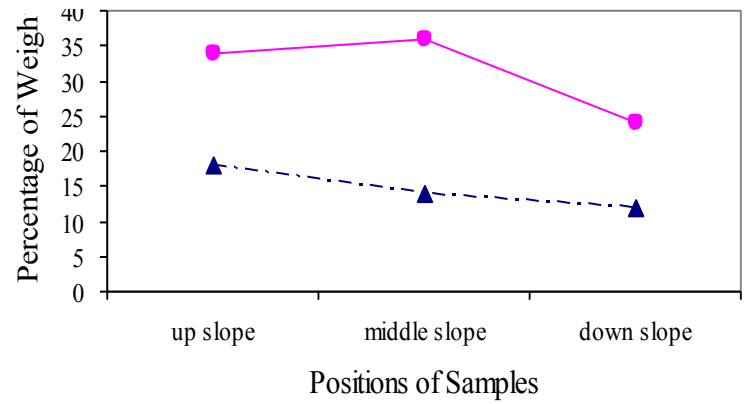

(b)

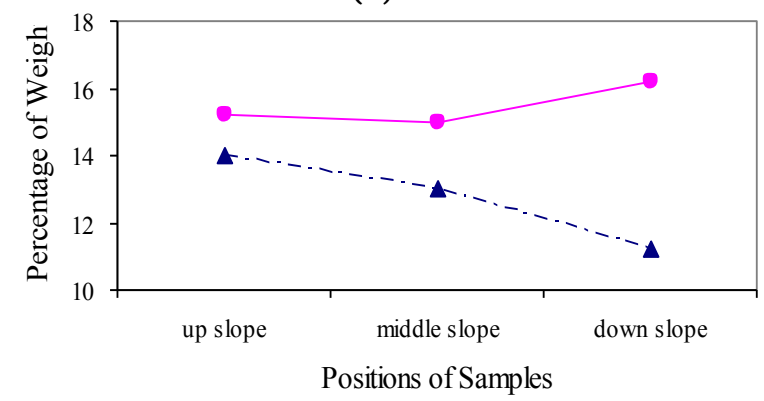

(d)
(a) particle size $<0.2 \mathrm{~mm}$.
(b) $0.2 \mathrm{~mm}<$ particle size $<2 \mathrm{~mm}$.
(c) $2 \mathrm{~mm}<$ particle size $<5 \mathrm{~mm}$.
(d) $5 \mathrm{~mm}<$ particle size $<10 \mathrm{~mm}$.
(e) particle size $>10 \mathrm{~mm}$.

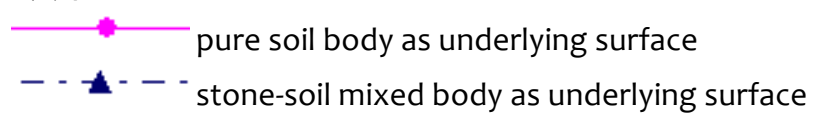

Figure 11 . Particle size analysis in different positions in slope for accumulative spoils. 
- - clay cutting edge $\quad \sim$ silt cutting edge $\quad-\mathbf{\Delta}-$ sandy cutting edge $\quad-$ Geotechnical cutting edge

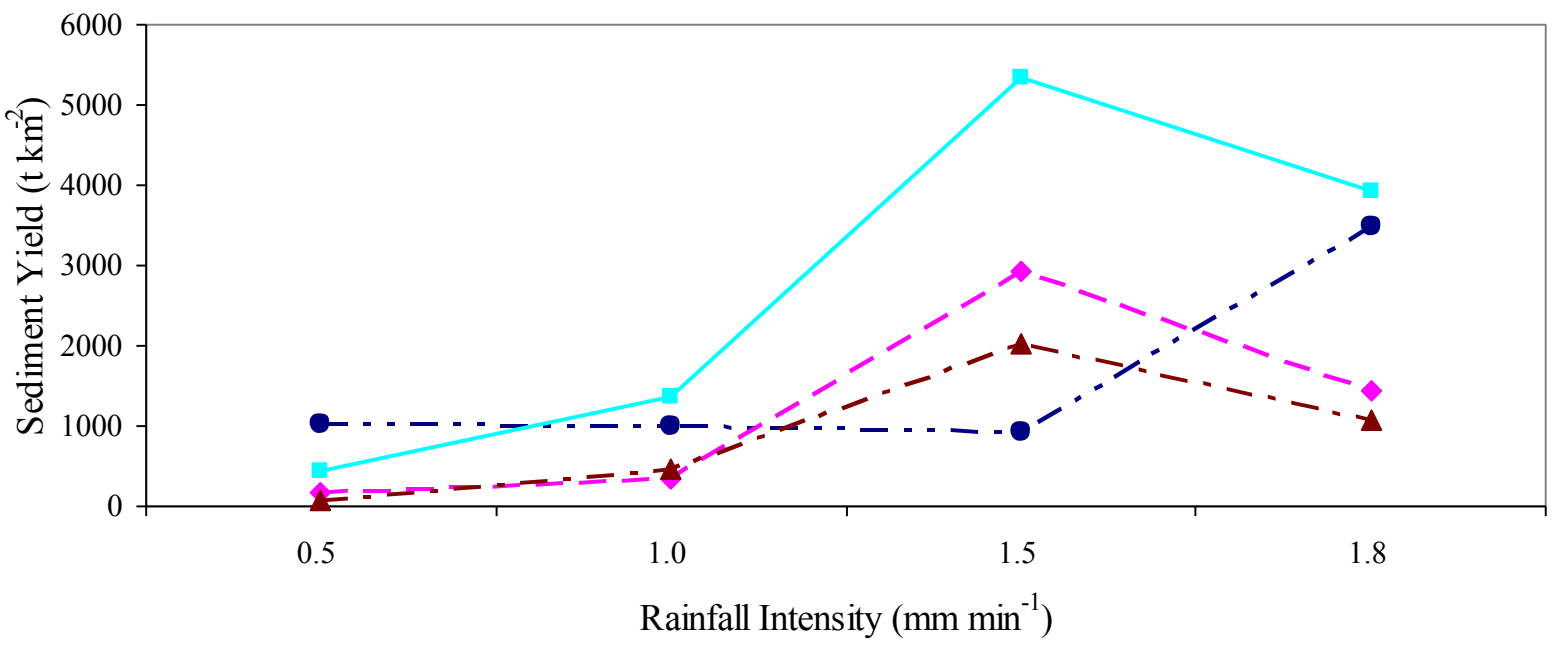

Figure 12. Sediment yield in different cutting edges in various rainfall intensities

\section{Sediment yields for accumulative spoils} with different underlying surfaces

Fig. 13 shows the relationships between sediment transport rate and rainfall intensity in the slope gradient of $35^{\circ}$ and $40^{\circ}$ in accumulative spoils with three types underlying surfaces. Similar trends for pure soil body and the stone-soil mixed body with the ratio 0.5 were build up, a slowly increment of sediment transport rate with the rainfall intensity

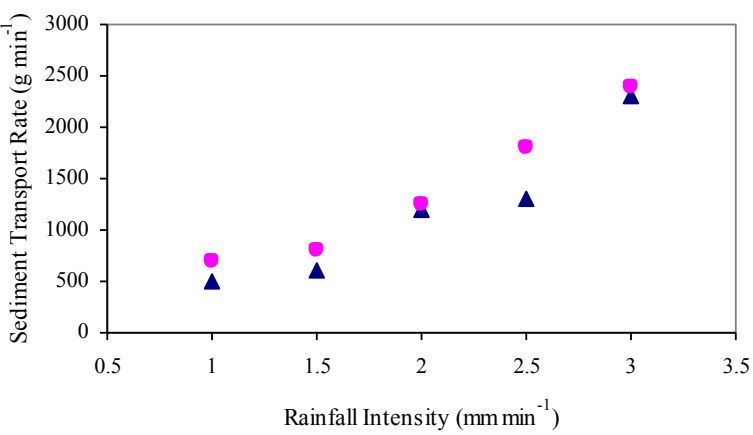

(a)

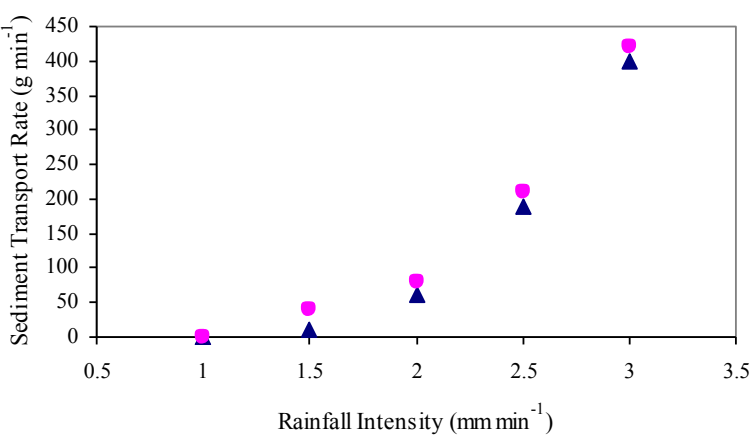

going up both suitable for them, which are different from the stone-soil mixed body with the ratio 0.5 , when the rainfall intensity increased, there was a rapid raising for sediment transport rate. In addition, it can be concluded that sediment transport rate for $40^{\circ}$ accumulative spoils were always greater than it while the slope gradient was $35^{\circ}$.

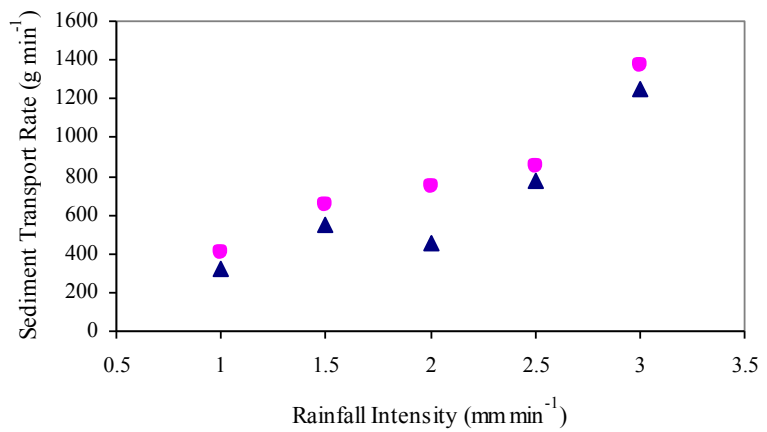

(b)

(a) pure soil body.

(b) stone-soil mixed body with the ratio 0.5 .

(c) stone-soil mixed body with the ratio 2.0.

- slop gradient at $35^{\circ}$

- slop gradient at $40^{\circ}$

Figure 13. Sediment transport rate in different accumulative spoils in various rainfall intensities 


\section{Relationship between wind erosion modulus and gravimetric moisture content}

The wind tunnel experiment was introduced to obtain the relationship between wind erosion modulus and gravimetric moisture content in different wind speeds, the results are shown in Fig. 14. It is clear that all erosion modulus are same trend with the gravimetric moisture content increasing. The less the moisture content is, the bigger the erosion modulus is.

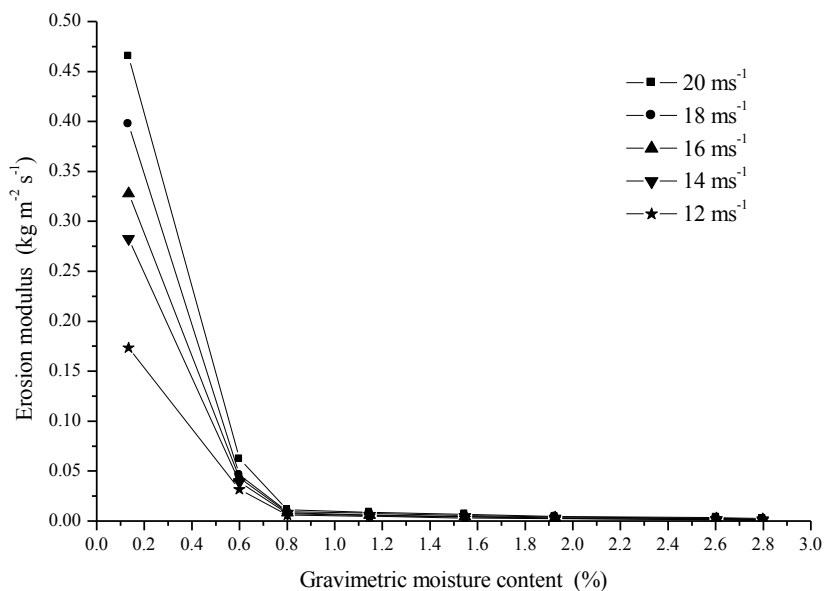

Figure 14. The relationship between wind erosion modulus and gravimetric moisture content

\section{Wind erosion amount changes while disturbance time varied}

Wind tunnel was also taken to evaluate effects on erosion amount of disturbance times. Take the same land use - cropland as an example, the experiments were held in Lanzhou and Yumen simultaneously. Results reveal that the highest erosion amount appeared in February, March and April. This means that more erosion can be caused while soil disturbance happened in spring. This will be useful for us to choose a proper time for developing a new construction activity to avoid severe erosions.

\section{Discussions on type classification of soil loss and models selection}

On the basis of field survey, laboratory analysis and experiment simulation, the types of soil loss caused by construction activities were classified, the characteristics for each type were summarized, the framework of models to estimate soil erosion were constructed.

\section{Type classification}

Generally, there are two types soil erosion in construction activities. The first one is soil loss by water, mainly including common soil disturbance, cutting edge, and accumulative spoil. The second one is soil loss caused by wind. Each type was classified further, and the details and characteristics were illustrated as follows.

\section{Characteristic of each type} sites

Soil erosion caused by water in construction

\section{Common soil disturbance}

(1) vegetation destruction : Plant cover decreased significantly due to original vegetation destruction during the process of construction activities. However, vegetation root system and original landform were not changed.

(2) soil surface disturbance: Soil surface was disturbed in construction process, this led to soil density reduced, but landform was kept as original.

(3) repeated rolling surface: Powdery regolith appeared while soil surface was dry and rolled repeatedly during the process of construction.

\section{Cutting edge}

(1) New cutting edge with catchment effect: Cutting edge was formed shorter than a rain season. It is easy to be washed by water come from upslope while top of cutting edge is lower than water divide, meantime, the there is no interception drain in the pathway between cutting edge and slope top.

(2) New cutting edge without catchment effect : Cutting edge was formed shorter than a rain season. It is almost impossible to be washed by water come from upslope while top of cutting edge is lower than water divide, however, the there are interception drains in the pathway between cutting edge and slope top.

(3) Stable cutting edge with catchment effect : Cutting edge was formed longer than a rain season. It has been washed by water come from upslope while t op of cutting edge is lower than water divide, meantime, the there is no interception drain in the pathway between cutting edge and slope top. 
(4) Stable cutting edge without catchment effect : Cutting edge was formed longer than a rain season. It has not been washed by water come from upslope while top of cutting edge is lower than water divide, meantime, the there is no interception drain in the pathway between cutting edge and slope top.

\section{Accumulative spoil}

(1) Accumulative spoil without converged upslope water: Accumulative spoil with single crown on flat surface distributes widely in this type. There is no upslope converged water, so no effects on it.

(2) Accumulative spoil with converged upslope water : Accumulative spoil with a big platform in crown, so upslope converged water made the erosion more severely as its wash effect topsoil.

(3) Thin accumulative spoil cling to slope: There is usually a surface of separation between accumulative spoil and original landform while the former was placed on the latter. Soil erosion amount can be increased significantly while slip surface formed in separation edge through infiltration.

\section{Soil erosion caused by wind in construction sites}

Original soil disturbance : Vegetation cover decreased or soil density reduced owing to grazing, reclamation or machine rolling. Landform is kept as original or just changed in part in this type.

Accumulation soil body : Numerous tailing produced in the process of mining or spoil caused by original soil disturbance were accumulated can form this type. Erosion is increased while height goes up in windward side.

Repeated rolling surface: Original soil structure was destructed under repeated rolling in construction sites. Under the circumstance of surface soil with low water content, powdery regolith formed, erosion risk is accordingly increased.

\section{Model framework}

The models framework to estimate erosion amount for construction site were clarified through selecting crucial factors, which were evaluated in field survey and simulation experiment. In general, models with format of USLE were primary selected. Some factors were considered to revise in different models.
Model framework for common soil disturbance

$$
A=R \cdot K \cdot L \cdot S \cdot C \cdot M
$$

Where, $A$ is soil loss, $R$ is rainfall erosive factor, $K$ is soil erodibility factor, $L$ is slope length factor, $S$ is slope steepness factor, $\mathrm{C}$ is plant cover factor, and $\mathrm{M}$ is the area of disturbance.

For the type of vegetation destruction, the crucial factor is $C$ because of the change of plant cover; for the type of soil surface disturbance and repeated rolling surface, while soil density changed, the factor $\mathrm{K}$ is also varied. In addition, for the long slope where experienced whole disturbance, $K, L$, and $C$ should be changed simultaneously.

\section{Model framework for cutting edge}

For cutting edge without catchment effect, the model framework was mentioned as follows:

$$
A=f(U, I, S, L)
$$

Where, $U$ is soil density, I is rainfall intensity.

For cutting edge with catchment effect, the quantities of catchment and persistent time have also been taken into consideration, so the model framework was changed as follows:

$$
A=f(U, D, S, L, T)
$$

Where, $D$ is quantities of catchment, $T$ is persistent time of upslope catchment.

\section{Model framework for accumulative spoil}

For accumulative spoil without converged upslope water, equation (1) can be also used to estimate erosion amount. However, for accumulative spoil with converged upslope water, a influence factor should be inclusive in model framework:

$$
A=k \cdot f(R, K, L, S)
$$

Where, $k$ is the coefficient of converged upslope water.

For the type of thin accumulative spoil cling to slope, except for erosion caused by water, it is not ignored to estimate erosion caused by gravity. So model to calculate soil loss includes two parts as follows:

$$
A=A_{W}+A_{G}=k \cdot f\left(R, K, L, S_{1}\right)+f\left(S_{2}, F, W\right)
$$

Where, Aw is soil loss caused by water, AG is soil loss caused by gravity, $k$ is coefficient of soil 
loss, $S_{1}$ is slope gradient of accumulative spoil, $S_{2}$ is slope steepness of original landform, $F$ is area of upload catchment, is the ratio of soil and stone in accumulative spoil.

\section{Model framework for soil erosion caused by wind in construction sites}

\subsubsection{Original soil disturbance}

For the type of original soil disturbance, wind erosion is influenced by particle size, wind speed, and plant cove, so the following equation can be taken to estimate:

$$
A=f(d, v, c)
$$

Where, $d$ is particle size factor, $v$ is wind speed, $\mathrm{C}$ is plant cover factor.

\section{Accumulation soil body}

Compare with flat surface erosion, accumulation soil body erosion is more severely due to speeding effect of wind in windward side. Taken into account of coefficient $f$, the following equation can be used to estimate wind erosion or slope of accumulation soil body:

$$
A=f\left(A_{0}, K . S, V\right)
$$

Where, $A_{0}$ is the wind erosion amount in flat ground, $\mathrm{k}$ is coefficient depends on slope gradient and length, $s$ is slope gradient of accumulation soil body.

\section{Repeated rolling surface}

Particle size changed apparently after repeated rolling, so while plant cover is ignored, equation (6) can be used to calculate erosion quantities in this circumstance.

\section{CONCLUSIONS}

It is challengeable to prevent and control the construction sites erosion due to large areas of soil exposed. This study has attempted to demonstrate the characteristic, classification, and crucial parameters in different models to generate information on soil erosion in construction sites.

The basic characteristics, such as slope gradient, slope length, soil depth, soil density, stone percentage and particle size, of cutting edges and accumulative spoil, were revealed successfully via field surveys and lab analysis. Main changes on sediment yields in different underlying surfaces were also obtained through simulation on rainfall.
Under the support of wind tunnel experiment, relationship between wind erosion modulus and gravimetric moisture content was analyzed; wind erosion amount changes were studied while disturbance time varied. Finally, the key parameters to contribute erosion in construction sites were selected to fulfill the estimation models framework.

To make that erosion estimation accurate, more experiments should be developed both in field and in labs to ascertain relationship between erosion amount and parameters. Specific models should be put forward to required detailed information on soil loss of construction sites in further studies.

\section{ACKNOWLEDGEMENTS}

The authors gratefully acknowledge the support for the reported study provided by the Ministry of Water Resources of China through the non-profit project of "Study on common technologies in soil loss calculation during construction activities" (No. of project 201001036). Thanks are also extended to Prof. Zuo Changqing at China Institute of Water Resources and Hydropower Research, Prof. Xie Yongsheng, Prof. Wang Wenlong at Institute of soil and water conservation of Chinese Academy of Sciences and Ministry of Water Resources, Prof. Zhang Pingcang at Institute of Yangtze River, Prof. Qu Jianjun at Cold and Arid Regions Environmental and Engineering Research Institute of Chinese Academy of Sciense, for assistance with filed survey, soil analysis and simulation experiments placement.

\section{REFERENCES}

Bhattarai, R., Kalita, P.K., Yatsu, Sh., Howard, H.R., Sevendsen, N.G., 2011. Evaluation of compost blankets for erosion control from disturbed lands. J. Environ. Manage. 92, 803-812.

Burton, G. A. and Pitt, Jr. R. E. 2002. Stormwater Effects Handbook - A ttolbox for watershed managers, scientists, and engineers. CRC Press LLC.

Chen, Y., Viadero Jr., R.C., Wei, X., Fortney, R., Hedrick, L.B., Welsh, S.A., Anderson, J.T., Lin, L.Sh., 2009. Effects of highway construction on stream water quality and macro invertebrate condition in a mid-Atlantic highlands watershed, USA. J. Environ. Qual. 38, 1672-1682.

Dong, J.Z., Zhang, K.L., Zhang, W.X., Shao, S.G., 2011. Highway waste dump shape and regional differences. Bulletin of Soil and Water Conservation (in Chinese): 3 (2), 163-167.

Forman, R.T.T. Deblinger, R.D., 2000. The ecological roadeffect zone of a Massachusetts (USA) suburban highway. Conservation Biology 14, 36-46. 
Hogan, D.M., Walbridge, M.R., 2007. Best management practices for nutrient and sediment retention in urban stormwater runoff. J. Environ. Qual. 36, 386-395.

Houser, D.L., Pruess, H., 2009. The effects of construction on water quality: a case study of the culverting of Abram Creek. Environ. Monit. Assess. 155, 431-432.

Jon Harbor. 1999. Engineering geomorphology at the cutting edge of land disturbance: erosion and sediment control on construction sites. Geomorphology, 31, 247-263.

Noura Bakr, David C. Weindorf, Yuanda Zhu, Allen E. Arceneaux, H.M. Selim, 2012. Evaluation of compost/mulch as highway embankment erosion control in Louisiana at the plot-scle. Journal of Hydrology, 468-469, 257-267.

SEWRPC (Southeastern Wisconsin Planning Commission). 1978. Sources of water Pollution in Southeastern Wisconsin 1975. Technical Report No. 21. Waukesha, WI.

Storey, B.B., McFalls, J.A., Godfrey, S.H., 1996. The use of compost and shredded brosh on rights-of-way for erosion control, Research Report 1352-2F. Texas Transportation Institute, College Station, TX.
US Geological Survey. 1970. The national atlas of the United States of America. US Government Printing Office, Washington DC.

USEPA, 2005. National management measures to control nonpoint source pollution from Urban areas. Management Measure 12: Evaluate Program Effectiveness. EPA-841-B-05004.

Willett, G. 1980. Urban erosion, in National Conference on Urban Erosion and Sediment Control: Institutions and Technology. EPA 905/9-80-002. U.S. Environmental Protection Agency.

Xu Xianli, Liu Wen, Kong Yaping, Zhang Keli, Yu Bofu, Chen Jiding, 2009. Runoff and water erosion on road sideslopes: Effects of rainfall characteristics and slope length. Transportation Research Part D, 14, 497-501. 